\title{
Concomitant use of drugs known to cause interactions with oral antiplatelets-polypharmacy in acute coronary syndrome outpatients in Finland
}

\author{
Tuire Prami $^{1}$ - Houssem Khanfir ${ }^{1} \cdot$ Pål Hasvold $^{2} \cdot$ Eeva Reissell $^{3} \cdot$ Juhani Airaksinen $^{4,5} \cdot$ Ville Kytö $^{4,5,6,7,8}$ (D
}

Received: 29 May 2019 / Accepted: 26 September 2019 / Published online: 26 November 2019

(C) The Author(s) 2019

\begin{abstract}
Purpose Use of oral antiplatelets (OAPs) is essential for preventing thrombotic events in patients with acute coronary syndrome (ACS). Effects of clopidogrel, prasugrel, and ticagrelor may be enhanced due to pharmacodynamic interactions, but as CYP substrates, they are prone to pharmacokinetic interactions too. The aim was to study polypharmacy in ACS patients following hospital discharge.

Methods This observational drug utilization study linked patient-level data from nationwide registers. The study population consisted of adult ACS patients discharged from Finnish hospitals in 2009-2013. Logistic regression was used to model the probability of drug-drug interactions with odd ratios for predefined predictors such as age, gender, and ACS type.

Results In the cohort of 54,416 ACS patients, 91\% of those treated with OAP received clopidogrel. Of clopidogrel-treated patients, $12 \%$ purchased warfarin at least once while on clopidogrel treatment. Old age, male sex, ST-elevation myocardial infarction as index event, and a history of previous ACS events were associated with an increased risk of warfarin-OAP interaction ( $p<0.001$ for all). Ibuprofen, and serotonergic drugs tramadol, citalopram, and escitalopram were the next most common drugs causing pharmacodynamic interactions. In general, concomitant use of drugs known to cause pharmacokinetic interactions was rare, but both esomeprazole and omeprazole were prescribed in more than $6 \%$ of clopidogrel-treated patients. Conclusions Warfarin and ibuprofen were the most commonly used concomitant medications causing pharmacodynamic interactions and potentially increasing the risk of bleeding in OAP-treated patients. Esomeprazole and omeprazole were used in clopidogrel-treated patients although there are alternatives available for gastric protection.
\end{abstract}

Keywords Clopidogrel $\cdot$ Prasugrel $\cdot$ Ticagrelor $\cdot$ Polypharmacy $\cdot$ Drug-drug interaction

Electronic supplementary material The online version of this article (https://doi.org/10.1007/s00228-019-02777-z) contains supplementary material, which is available to authorized users.

Ville Kytö

ville.kyto@utu.fi

1 EPID Research, Espoo, Finland

2 AstraZeneca Nordic Baltic, Södertälje, Sweden

3 National Institute for Health and Welfare, Helsinki, Finland

4 Heart Center, Turku University Hospital, PO Box 52, FI-20521 Turku, Finland
5 Department of Medicine, University of Turku, Turku, Finland

6 Research Centre of Applied and Preventive Cardiovascular Medicine, University of Turku, Turku, Finland

7 Centre for Population Health Research, Turku University Hospital and University of Turku, Turku, Finland

8 Administrative Centre, Hospital District of Southwest Finland, Turku, Finland 


\section{Introduction}

Adenosine diphosphate $\mathrm{P} 2 \mathrm{Y}_{12}$ receptor is an important pharmacological target for inhibition of platelet aggregation and prevention of atherothrombotic events [1]. Use of oral $\mathrm{P}_{2} \mathrm{Y}_{12}$ inhibitors (OAPs) is an effective therapy for inhibiting platelet activity in patients with acute coronary syndrome (ACS), and required for prevention of thrombotic events after stent implantation in percutaneous coronary intervention (PCI) [2].

Clopidogrel is a prodrug requiring metabolic activation for its clinical effectiveness as a $\mathrm{P} 2 \mathrm{Y}_{12}$ inhibitor. The activation requires two sequential oxidative steps: formation of 2-oxo-clopidogrel followed by conversion to the active metabolite. CYP2C19 contributes substantially to both oxidative steps, and CYP3A4 to the second oxidative step [3]. Prasugrel is also a prodrug metabolized in a two-step process. Formation of the active metabolite is initiated by plasma esterases followed by a single CYP-dependent (primarily CYP3A4 and CYP2B6) activation step [3]. Unlike clopidogrel, prasugrel does not have a hydrolyze inactivation pathway that consumes the majority (85\%) of the absorbed clopidogrel dose [3]. Ticagrelor undergoes extensive CYP3A4-mediated metabolism to produce the active metabolite [4]. Both the parent drug and the active metabolite inhibit directly but reversibly the $\mathrm{P}_{2} \mathrm{Y}_{12}$ receptor [4]. This rapid reversible action together with the general pharmacokinetic profile of ticagrelor profile contributes to the need of twice daily dosing. Thus, co-administration of notable inhibitors or inducers of corresponding CYP enzymes results in interactions with OAPs $[1,4]$. In addition, due to their mechanism of action, OAPs additionally or synergistically interact with other drugs affecting platelet function, such as selective serotonin reuptake inhibitors (SSRIs) [5], increasing the risk of excess anticoagulation. Pharmacokinetics of clopidogrel is furthermore hindered by the SSRI drug fluoxetine [6].

Multidrug therapy itself increases the risk of drug-drug interactions. For example, a proton pump inhibitor (PPI) such as omeprazole is often added to decrease the risk of gastrointestinal (GI) bleeding related to dual antiplatelet therapy (DAPT) although omeprazole is a CYP2C19 inhibitor and decreases the effectiveness of clopidogrel therapy [7]. OAPs not only may be the victim drugs in interactions but also may affect the kinetics of other drugs, as the inhibition of simvastatin metabolism by ticagrelor demonstrates [3].

The aim of this study was to investigate polypharmacy in patients discharged from hospitals after ACS in Finland. The main focus was on concomitant medication with a potential to cause clinically significant drug-drug interactions with OAPs.

\section{Methods}

\section{Study population}

This nationwide data linkage study was performed in adult ACS patients discharged from Finnish hospitals after unstable angina pectoris (ICD-10 code: I20.0) or myocardial infarction (MI) (ICD-10 code: I21) in 2009-2013. The first ACS event during the study period was considered the index event. The data on diagnoses and hospitalization periods originated from The Care Register for Health Care run by The National Institute for Health and Welfare. The cohort formation is described more in detail previously [8].

\section{Data collection}

Medication data originated from the prescription register of The Social Insurance Institution. We received data on reimbursed prescriptions (such as cardiovascular drugs, gastrointestinal protection, antidiabetics) during the study period. In the study database, the analyses were based on Anatomical Therapeutic Chemical Classification System (ATC) codes. Additional information on filled prescriptions were purchase dates, Vnr numbers (identifying the packages), package sizes, number of packages, and ready-calculated total amount purchased in defined daily doses (DDD). OAP exposure period definition was based on the number of purchased tablets since the outpatient dosing is consistent for all: 1 tablet of clopidogrel, 1 tablet of prasugrel $(5 \mathrm{mg}$ or $10 \mathrm{mg}$ but not varying), or 2 tablets of ticagrelor. In case of switches in OAP use, the exposure period of the new OAP was considered to start immediately at the time of purchase, and the possible remaining tablets of the old OAP were considered not used. Baseline medication use prior to the index ACS event was searched for 120 days prior to the ACS hospitalization. The medication had to be ongoing (in terms of DDDs) at the time of ACS hospitalization to be taken into account. In general, co-medication was surveyed as purchase dates within 120 days after the discharge.

\section{Drug-drug interaction periods}

In a four-level classification of the interaction severity in SFINX, C refers to a clinically significant interaction that can be managed, e.g., by dose adjustments, and $\mathrm{D}$ to a clinically significant interaction best to be avoided. Drugs causing $\mathrm{C}$ level and D level drug-drug interactions with clopidogrel, prasugrel, and ticagrelor were searched in the SFINX interaction database [9] cited online on 18 June 2014. The number of different drug-drug interactions in OAP-treated patients was measured by purchases of the interactive drugs during the specific OAP treatment periods. A sample case of this analysis is presented in Fig 1. If the OAP was started or switched during ongoing interaction medication (based on DDDs) the interactive medication was considered to be withdrawn at the time of new OAP initiation (Fig 1). The calculation of drugdrug interaction periods was done for up to 12 months after the discharge. The follow-up ended at the time of death, 
Fig 1 Drug-drug interaction period specification by timedependent OAP-specific exposure in a sample patient

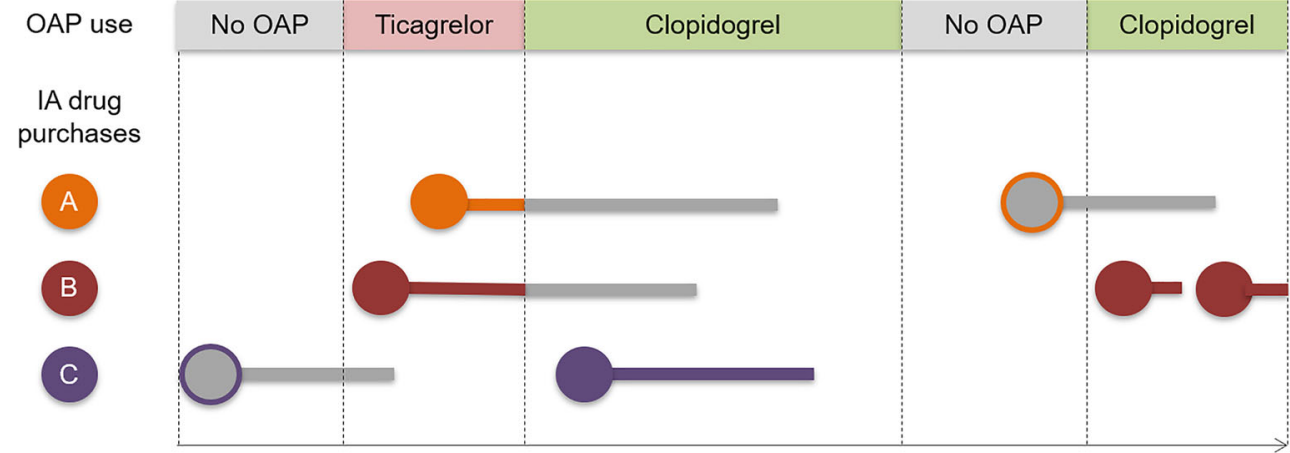

Time (max 12 months)

\begin{tabular}{|c|c|c|c|c|}
\cline { 2 - 5 } Results & Interaction & Ticagrelor & Clopidogrel & Prasugrel \\
\cline { 2 - 5 } & A & YES & NO & N/A \\
\hline B & YES & YES (1) & N/A \\
\hline C & NO & YES & N/A \\
\hline
\end{tabular}

moving abroad, or on 31 December 2013, whichever occurred first.

\section{Statistical analysis}

$\mathrm{R}$ language was used in all data management and statistical analysis. The concomitant use of the drugs known to interact with specific OAPs was studied time-dependently for 1 year after the discharge. Logistic regression was used to model the probability of concomitant use of warfarin, non-steroidal antiinflammatory drugs (NSAID), SSRIs, and PPIs (separately for each) with any OAP during any time of the follow-up. This model was simultaneously adjusted for a set of predefined predictors (age, gender, type of index ACS event, invasive treatment related to index event, major bleedings history, and history of previous ACS events). All covariate values were available for all patients in this analysis. Odd ratios for predefined predictors were reported along with $95 \%$ confidence intervals $(\mathrm{CI})$.

\section{Results}

In the cohort of 54,416 ACS patients, the mean age at baseline was 72 years, and $60 \%$ of the patients were male. The cohort characteristics have been described in more details previously [8]. Within 7 days after the hospital discharge, $49 \%$ of the ACS patients started OAP medication, $91 \%$ of these patients started treatment with clopidogrel.

\section{Baseline drug usage}

At baseline, $25 \%$ of the patients did not have any medications (Supplement Table 1). The median number of ongoing baseline drugs was 2 , and $16 \%$ of the patients had more than 4 drugs in their baseline regimen. The maximum number of ongoing drugs for a single patient was 14. Among clopidogrel users, $30 \%$ of the patients did not have any drug treatment at the baseline while in the non-OAP group of patients, this proportion was $20 \%$. On the other hand, five or more drugs were used in $14 \%$ and $19 \%$ of patients of these groups, respectively, at the time of the ACS event. Both in prasugrel and ticagrelor users, the number of baseline drugs was smaller (median 1) than in clopidogrel or non-OAP users (median 2).

The most commonly used drugs at baseline were statins, beta blockers, angiotensin-converting-enzyme (ACE) inhibitors, angiotensin II receptor blockers (ARBs), and calcium channel blockers (Table 1). Nitrate was more commonly used in non-OAP group (24\%) than in clopidogrel (16\%), prasugrel $(5 \%)$, or ticagrelor $(9 \%)$ groups. PPI medication was in use in $13 \%$ of patients who became OAP users, and in $18 \%$ of them who did not start treatment with OAP after ACS. The respective proportions for warfarin were $3 \%$ and $8 \%$, and for antidiabetic drugs, $16 \%$ and $19 \%$.

\section{Drug initiation}

Of those OAP-treated patients who did not have statin in their regimen at baseline, $93 \%$ started treatment with statins within 120 days after the hospital discharge (Table 1). This rate in non-OAP-treated patients was $58 \%$. In case of beta blockers, the initiation rates were $90 \%$ in OAP-treated patients and $76 \%$ in non-OAP-treated patients. For nitrates, the respective values were $75 \%$ and $57 \%$, and for ACE inhibitors, $49 \%$ and $28 \%$, but for ARBs, only $10 \%$ and $8 \%$. Warfarin was initiated in $8 \%$ of OAP users and in $20 \%$ of the patients in the non-OAP group. PPI was initiated as a new drug in more than $30 \%$ of patients in all patient groups. Of the whole cohort, 


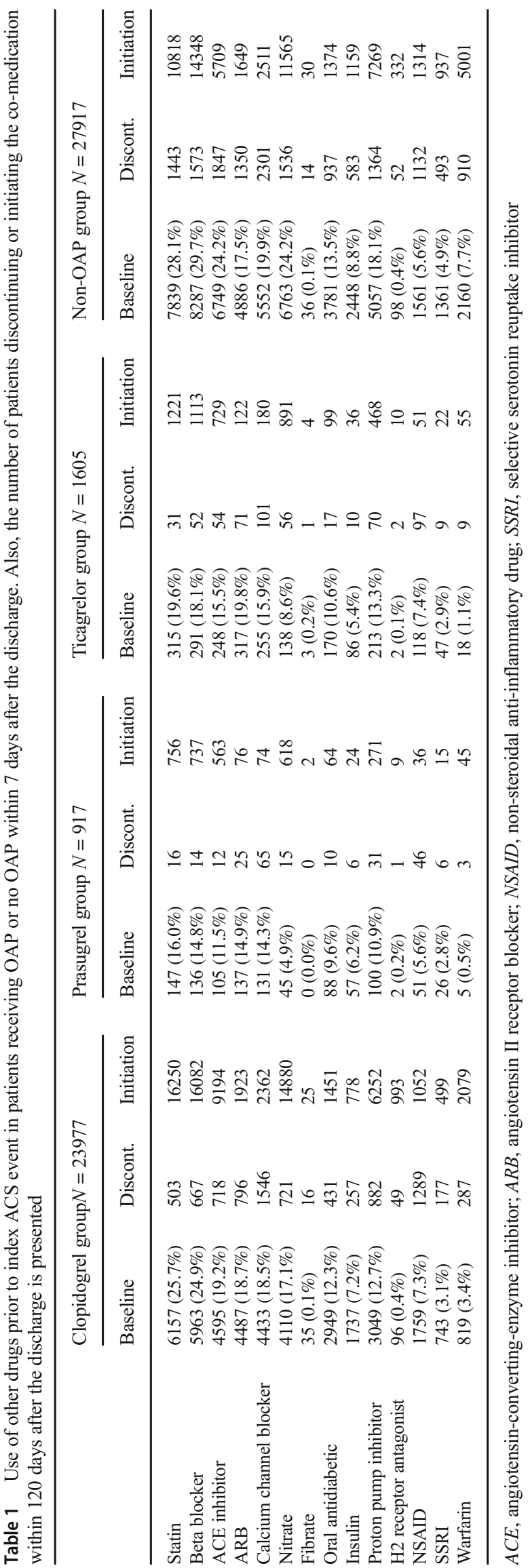

6-7\% of the patients became new users of oral antidiabetic medication after ACS.

\section{Drug discontinuation}

Treatment with calcium channel blockers initiated prior to index event was discontinued in $35-50 \%$ of the patients in all groups within 120 days after discharge from hospital (Table 1). Corresponding discontinuation rate was 19-36\% for both PPI and SSRI medication. Warfarin was withdrawn in $36 \%$ of OAP users and in $42 \%$ of non-OAP users, respective rates for nitrates being $18 \%$ and $23 \%$. ACE inhibitor and ARB discontinuation was more common among non-OAP patients than in OAP-treated patients: $27-28 \%$ vs $16-18 \%$.

\section{Drug-drug interaction periods}

At the time of the ACS event, $32 \%$ of the patients who started treatment with clopidogrel were using one or more concomitant medications with potential for clopidogrel drug-drug interactions. In the prasugrel group, the corresponding rate was $22 \%$ and in the ticagrelor group $25 \%$. In comparison, in the non-OAP group, the use of drugs with potential for interactions with OAPs was $39 \%$.

Warfarin was the most commonly purchased drug known to cause pharmacodynamic interactions with OAPs (Table 2). More than 3400 patients on clopidogrel, representing $12 \%$ of these people, purchased warfarin at least once when clopidogrel was ongoing in their regimen. Ibuprofen (defined as reimbursed prescriptions) was the second most common drug causing pharmacodynamic interactions with OAPs. The use of serotonergic drugs tramadol, citalopram, and escitalopram was nearly as common. Well-documented D level interactions of esomeprazole and omeprazole with clopidogrel occurred both in more than $6 \%$ of the clopidogrel users (Table 2). The interaction proportions of prasugrel and ticagrelor with other drugs were less than those of clopidogrel in general, with the exception of the concomitant use of ticagrelor with simvastatin that occurred in $42 \%$ of the ticagrelor users.

\section{Predictors of drug-drug interaction periods}

Old age was associated with about a two-fold increase in the risk of warfarin-OAP interaction, the OR being the highest in $>65$ - to $\leq 75$-year-old patients compared with $\leq 65$ years old ( $p<0.001$ for all) (Supplement Table 2). ST-elevation myocardial infarction (STEMI) as index event, major bleeding history, and previous ACS events increased the risk of concomitant use of these drugs by $30 \%$. Concomitant use of warfarin was $20 \%$ more common in male patients than in female patients $(p<0.001)$. NSAID use together with OAPs decreased gradually by age, and concomitant SSRI medication 
Table 2 Number of clopidogrel, prasugrel, and ticagrelor-treated patients during the first year of follow-up who made purchases of interactive drugs during the OAP exposure

\begin{tabular}{|c|c|c|c|c|c|c|}
\hline IA drug and effect type & \multirow{2}{*}{\multicolumn{2}{|c|}{$\begin{array}{c}\text { CLOPIDOGREL } \\
\text { IA class, N, (\%) }\end{array}$}} & \multicolumn{2}{|c|}{ PRASUGREL } & \multicolumn{2}{|c|}{ TICAGRELOR } \\
\hline & & & & ass, $\mathrm{N},(\%)$ & & ass, $\mathrm{N},(\%)$ \\
\hline \multicolumn{7}{|c|}{ DYNAMIC (increasing bleeding risk) ${ }^{\dagger}$} \\
\hline Warfarin & $\mathrm{C} 3$ & $3425(12.12 \%)$ & & $62(5.11 \%)$ & & $74(3.83 \%)$ \\
\hline Ibuprofen & $\mathrm{CO}$ & $1801(6.37 \%)$ & $\mathrm{C} 0$ & $52(4.29 \%)$ & $\mathrm{C} 0$ & $80(4.14 \%)$ \\
\hline Tramadol & $\mathrm{C} 0$ & $1501(5.31 \%)$ & $\mathrm{C} 0$ & $44(3.63 \%)$ & $\mathrm{C} 0$ & $69(3.57 \%)$ \\
\hline Citalopram & $\mathrm{C} 0$ & $866(3.07 \%)$ & & $20(1.65 \%)$ & $\mathrm{C} 2$ & $25(1.29 \%)$ \\
\hline Escitalopram & $\mathrm{C} 0$ & $658(2.33 \%)$ & $\mathrm{C} 0$ & $22(1.81 \%)$ & $\mathrm{C} 2$ & $33(1.71 \%)$ \\
\hline Diclofenac & $\mathrm{CO}$ & $656(2.32 \%)$ & $\mathrm{C} 0$ & $26(2.14 \%)$ & $\mathrm{C} 0$ & $33(1.71 \%)$ \\
\hline Etoricoxib & $\mathrm{C} 0$ & $570(2.02 \%)$ & $\mathrm{C} 0$ & $14(1.15 \%)$ & $\mathrm{C} 0$ & $21(1.09 \%)$ \\
\hline Naproxen & $\mathrm{C} 3$ & $415(1.47 \%)$ & $\mathrm{C} 0$ & $12(0.99 \%)$ & $\mathrm{C} 0$ & $24(1.24 \%)$ \\
\hline Meloxicam & $\mathrm{C} 0$ & $313(1.11 \%)$ & $\mathrm{C} 0$ & $2(0.16 \%)$ & $\mathrm{C} 0$ & $7(0.36 \%)$ \\
\hline Venlafaxin & $\mathrm{CO}$ & $236(0.84 \%)$ & $\mathrm{C} 0$ & $11(0.91 \%)$ & $\mathrm{C} 0$ & $8(0.41 \%)$ \\
\hline Duloxetine & $\mathrm{CO}$ & $211(0.75 \%)$ & $\mathrm{CO}$ & $10(0.82 \%)$ & $\mathrm{C} 0$ & $10(0.52 \%)$ \\
\hline Sertraline & C0 & $142(0.50 \%)$ & $\mathrm{C} 0$ & $4(0.33 \%)$ & $\mathrm{C} 2$ & $12(0.62 \%)$ \\
\hline Ketoprofen & $\mathrm{C} 0$ & $139(0.49 \%)$ & $\mathrm{C} 0$ & $2(0.16 \%)$ & $\mathrm{C} 0$ & $7(0.36 \%)$ \\
\hline Fluoxetine & $\mathrm{CO}$ & $88(0.31 \%)$ & $\mathrm{C} 0$ & $3(0.25 \%)$ & $\mathrm{C} 2$ & $5(0.26 \%)$ \\
\hline Celecoxib * & $\mathrm{Cl} *$ & $76(0.27 \%) *$ & $\mathrm{CO}$ & $1(0.08 \%)$ & $\mathrm{CO}$ & $3(0.16 \%)$ \\
\hline Indometacin & Co & $63(0.22 \%)$ & $\mathrm{C} 0$ & $1(0.08 \%)$ & $\mathrm{C} 0$ & $0(0.00 \%)$ \\
\hline Paroxetine & C0 & $63(0.22 \%)$ & $\mathrm{CO}$ & $2(0.16 \%)$ & $\mathrm{C} 2$ & $3(0.16 \%)$ \\
\hline Dabigatran & & $30(0.11 \%)$ & & $3(0.25 \%)$ & $\mathrm{C} 0$ & $1(0.05 \%)$ \\
\hline Etodolac & Co & $30(0.11 \%)$ & & $0(0.00 \%)$ & $\mathrm{C} 0$ & $0(0.00 \%)$ \\
\hline Clomipramine & $\mathrm{CO}$ & $17(0.06 \%)$ & $\mathrm{C} 0$ & $2(0.16 \%)$ & $\mathrm{C} 0$ & $1(0.05 \%)$ \\
\hline Nabumetone & $\mathrm{C} 0$ & $13(0.05 \%)$ & $\mathrm{CO}$ & $0(0.00 \%)$ & $\mathrm{C} 0$ & $0(0.00 \%)$ \\
\hline Fluvoxamine * & $\mathrm{C} 0 *$ & $11(0.04 \%) *$ & $\mathrm{C} 0$ & $1(0.08 \%)$ & $\mathrm{C} 0$ & $0(0.00 \%)$ \\
\hline Tolfenamic acid & C0 & $7(0.02 \%)$ & $\mathrm{C} 0$ & $2(0.16 \%)$ & $\mathrm{C} 0$ & $0(0.00 \%)$ \\
\hline Mefenamic acid & Co & $4(0.01 \%)$ & $\mathrm{C} 0$ & $0(0.00 \%)$ & $\mathrm{C} 0$ & $0(0.00 \%)$ \\
\hline Milnacipran & $\mathrm{C} 0$ & $4(0.01 \%)$ & $\mathrm{C} 0$ & $0(0.00 \%)$ & $\mathrm{C} 0$ & $0(0.00 \%)$ \\
\hline \multicolumn{7}{|c|}{ KINETIC (increasing coagulation risk) } \\
\hline Esomeprazole & D4 & $1886(6.68 \%)$ & $\mathrm{C} 0$ & $49(4.04 \%)$ & & \\
\hline Omeprazole & D4 & $1781(6.30 \%)$ & & & & \\
\hline Fluconazole & $\mathrm{C} 0$ & $265(0.94 \%)$ & & & & \\
\hline Morphine & $\mathrm{C} 3$ & $17(0.06 \%)$ & & & & \\
\hline Fluvoxamine & $\mathrm{C} 0$ & $11(0.04 \%)$ & & & & \\
\hline Carbamazepine & & & & & Do & $5(0.26 \%)$ \\
\hline Phenytoin & & & & & Do & $1(0.05 \%)$ \\
\hline \multicolumn{7}{|c|}{ KINETIC (increasing bleeding risk) ${ }^{8}$} \\
\hline Amiodarone & & & & & $\mathrm{C} 0$ & $14(0.72 \%)$ \\
\hline Ditiazem & & & & & $\mathrm{C} 3$ & $8(0.41 \%)$ \\
\hline Clarithromycin & & & & & Do & $7(0.36 \%)$ \\
\hline Ciclosporin & & & & & $\mathrm{C} 0$ & $2(0.10 \%)$ \\
\hline Erythromycin & & & & & D0 & $1(0.05 \%)$ \\
\hline Verapamil & & & & & D0 & $1(0.05 \%)$ \\
\hline \multicolumn{7}{|c|}{ OTHER KINETIC (OAP potentiating the effect of the IA drug) } \\
\hline Simvastatin & & & & & $\mathrm{C} 3$ & $811(41.98 \%)$ \\
\hline Celecoxib & $\mathrm{Cl}$ & $76(0.27 \%)$ & & & & \\
\hline Bupropion & $\mathrm{C} 3$ & $41(0.15 \%)$ & & & & \\
\hline Digoxin & & & & & C3 & $8(0.41 \%)$ \\
\hline
\end{tabular}

IA, interaction; OAP, oral antiplatelet

Interaction categories as stated by Böttiger et al. 2009 [9]: C, Clinically relevant interaction that can be handled, e.g., by dose adjustments; D, Clinically relevant interaction. The combination is best avoided; 0 , Data derived from extrapolation on the basis of studies with similar drugs; 1 , Data derived from incomplete case reports and/or in vitro studies; 2, Data derived from well-documented case reports; 3, Data derived from studies among healthy volunteers and/or pilot studies among patients; 4, Data derived from controlled studies in relevant patient populations

${ }^{\dagger}$ Drugs listed to have dynamic interaction in co-use with the OAPs, but with no concomitant treatment periods in the study population: aceclofenac, acemetacin, acetylsalicylic acid, dexibuprofen, dexketoprofen, flurbiprofen (even topical), kebuzone, ketorolac, lepirudin, lornoxicam, lumiracoxib, meclofenamic acid, metamizole, nifluminic acid, nimesulide, parecoxib, phenylbutazone, piroxicam, proglumetacin, rofecoxib, sulindac, tenoxicam, tiaprofenic acid, valdecoxib, and ipilimumab (interaction mechanism unknown)

${ }^{\star}$ Drugs listed to have kinetic interaction with potential to increase coagulation risk, but with no concomitant treatment periods in the study population: cimetidine (with clopidogrel), voriconazole (with clopidogrel), and ritonavir (with prasugrel), as well as the following drugs in co-use with ticagrelor: enzalutamide, mitotane, phenobarbital, primidone, rifampicin, and rifamycin

${ }^{\S}$ Drugs listed to have kinetic interaction in co-use with ticagrelor with potential to increase bleeding risk, but with no concomitant treatment periods in the study population: atazanavir, crizonib, darunavir, erythromycin, fosamprenavir, indinavir. itraconazole, ketoconazole, lopinavir, nelfinavir, posaconazole, quinidine, quinine, ritonavir, saquinavir, telithromycin, tipranavir, troleandomycin, and voriconazole

${ }^{\text {II }}$ Drugs listed to have kinetic interaction with OAPs, but with no concomitant treatment periods in the study population: cyclophosphamide (clopidogrel), sibutramine (clopidogrel), and midazolam (ticagrelor) 
was prescribed to approximately $40 \%$ fewer OAP patients of $>65$ years than $<65$ years $(p<0.001$ for all). NSAIDs were more often used in OAP-treated patients with unstable angina pectoris than in OAP-treated patients with MI as the index event, and in patients with history of previous ACS events. SSRI used together with OAPs was twice more common among female patients than in male patients $(p<0.001)$ and $35 \%$ less common in patients undergoing invasive treatment than in patients treated conservatively $(p<0.001)$. Patients with previous bleeding or ACS event history were in increased risk of SSRI interactions. Concomitant PPI use increased gradually by age and was more common in women (OR 1.37) as well as patients with previous bleeding or ACS event history (ORs 1.53 and 1.51) $(p<0.001$ for all).

\section{Discussion}

This real-life registry study of more than 54,000 ACS patients describes the occurrence and predictors of drug-drug interactions with oral antiplatelet therapy defined as concomitant treatment periods. After the ACS event, $71 \%$ of patients in this cohort were treated with a beta blocker, $65 \%$ with a statin, $55 \%$ with either an ACE inhibitor or an ARB, and $49 \%$ with an OAP [8]. In a Swedish setting with almost 100,000 MI patients, $89 \%$ of the patients were treated with a beta blocker, $79 \%$ with a statin, and $69 \%$ with clopidogrel after discharge [10]. After the ACS hospitalization and OAP initiation, a statin and a beta blocker were initiated to more than $90 \%$ of the patients not having these drugs in their regimen at baseline. This is well in line with the current guidelines [11, 12]. Both in the present study and the recent Swedish study [10], ACE inhibitor was clearly the more common choice to block the renin-angiotensin-aldosterone system than ARB.

Oral antiplatelet treatment was used less commonly in warfarin treated ACS patients in our cohort [8]. Regardless, warfarin was the most commonly used drug with the potential to cause pharmacodynamic interactions in OAP patients. The risk of this interaction increased not only in the elderly but also in the patients with history of major bleedings and previous ACS events. Definition of warfarin exposure periods based on prescription data is difficult since the dosing is variable. On the other hand, the dosing of OAPs is uniform. Thus, we recognized the possibility for warfarin-OAP interactions if a warfarin purchase occurred during ongoing OAP medication. There is, however, the option of OAP cessation prior to the end of the purchased package due to warfarin initiation. This occurrence cannot be determined with certainty in a retrospective registry setting. At the time of the study planning, we noticed that warfarin was not listed as an interactive drug for prasugrel and ticagrelor in SFINX but we included these drug pairs in our study (gray cells in Table 2). By personal communication with the company producing this database, we were told that the creation of the database did not start with the most obvious drug pairs, but as the drug-drug interactions most difficult to remember do not exhibit a class effect, the work was started with pharmacokinetic interactions. Later we found SFINX to include warfarin-prasugrel (C3) and warfarin-ticagrelor $(\mathrm{C} 0)$ interactions (cited online 07 September 2016).

The second most common drug with potential to cause pharmacodynamic interaction with OAPs, and thus increasing the risk of bleeding, was ibuprofen. Ibuprofen use is possibly underestimated in our study setting, as it is also available as over the counter (OTC) products, and the present data is based on reimbursed prescriptions. ORs for the concomitant use of NSAIDs during OAP treatment showed increased risk in young ( $\leq 65$ years old) patients as well as in patients with unstable angina pectoris as index event and patients with history of previous ACS events. In a nationwide study from Denmark, it was concluded that the use of NSAIDs together with antithrombotic medication increased the risk of bleeding and excess thrombotic events even in short-term concomitant use in MI patients [13]. Effects of drug-drug interactions in the current cohort remain to be studied.

In our cohort, a PPI was initiated in the regimen as a new drug after ACS event in more than $30 \%$ of patients in all patient groups. In the OAP-treated patients, PPI use increased by age was higher in female than in male patients, and was especially highlighted in patients with history of major bleedings or previous ACS events. Of all PPIs, omeprazole and esomeprazole are potent inhibitors of CYP2C19. Omeprazole and esomeprazole have been shown to reduce clopidogrel $(75 \mathrm{mg} /$ day $)$ efficacy and increase the prevalence of low responders to clopidogrel $[14,15]$. Ferreiro et al. reported that even a 12 -h separation of dosing could not prevent drug interactions between omeprazole and clopidogrel [14]. Moceri et al. found that doubling the dose of clopidogrel could restore the loss of antiplatelet effect by esomeprazole [15]. In SFINX [9], omeprazole and esomeprazole interactions are classified as D type interactions (not manageable with dosing but best avoided). These two interactions were the most common pharmacokinetic interactions among clopidogrel users with more than $6 \%$ of clopidogrel users for the two PPIs in our data. Also in an Italian cohort study, clopidogrelomeprazole pair was the most probable drug-drug interaction [16]. It might be potentially beneficial if omeprazole and esomeprazole would not be concomitantly used with clopidogrel [17]. The US Food and Drug Administration issued safety warnings against this combination in 2009 and 2010 [18]. For clinicians, it should not be difficult to avoid these situations as there are alternatives such as pantoprazole, lansoprazole or rabeprazole [3], or the use of high-dose H2 receptor blocker other than cimetidine, a known inhibitor of CYP2C19, available [5]. Furthermore, counseling of OAP 
patients to avoid omeprazole and esomeprazole is also important as both are also available OTC.

Aging and a high number of drugs increase the risk of drugdrug interactions. In a cross-sectional assessment in elderly nursing homes in Finland, 4.8\% of the residents were exposed to $D$ class interactions [19]. The mean number of drugs used in this study was 7.9 and $43 \%$ of the patients had more than eight medications. In our cohort, the mean age was 72 years and $16 \%$ of the patients had five or more drugs in their baseline regimen. Polypharmacy of five or more drugs was more common in the non-OAP group (19\%) than in the OAP group (13\%) possibly reflecting underuse of OAP therapy in patients with multiple co-morbidities. Higher age, dementia, and atrial fibrillation were identified as independent factors decreasing the probability to OAP initiation [8].

In the present study, concomitant use of SSRIs potentially increasing the bleeding risk in co-use with OAPs was most common in the youngest patient group. Most likely, this interaction, in which serotonergic activity is increased by SSRIs (or tramadol), was not recognized by treating physicians as patients receiving these drugs included even those with a history of major bleeding. Notably, female patients received SSRIs together with OAPs twice as often as male patients.

In our data, clopidogrel was the most commonly prescribed OAP. Clopidogrel is a cornerstone in DAPT treatment, but treatment with clopidogrel has, however, disadvantages: two-step activation process, genetic polymorphism of CYP2C19, large inter-individual variability in platelet response, delayed onset of action, and drug-drug interaction potential $[1,20]$. Prasugrel and ticagrelor have been introduced to the market more lately and are being increasingly used. Prasugrel is a prodrug that requires metabolic activation for irreversible platelet inhibition. Ticagrelor, a reversible platelet inhibitor, is a CYP3A4 substrate and inhibitor thus involved in CYP-mediated drug-drug interactions [1].

In the present study, $4 \%$ of prasugrel users bought prescribed esomeprazole during their OAP treatment. Concomitant use of prasugrel and esomeprazole is suspected to cause a potential interaction by reducing prasugrel bioavailability due to decreased gastrointestinal $\mathrm{pH}$. At the time of study planning, this interaction was listed as $\mathrm{C}$ class interaction in SFINX, but afterwards, the classification has been downgraded to class A - a negligible interaction with no clinical significance (cited online 10 September 2016). Thus it can be concluded that prasugrel was not involved in significant pharmacokinetic interactions in our study.

Ticagrelor significantly increases the plasma levels of CYP3A4 substrates such as simvastatin [1]. Our results show that $42 \%$ of ticagrelor users purchased simvastatin during their OAP treatment suggesting that ticagrelor-simvastatin interaction may not be well known among physicians. We cannot, however, exclude the possibility that interaction was managed with dose adjustments, as our data did not include dosing information. Ticagrelor purchases have been collected to the prescription register since 2012 when the reimbursement status was given for ticagrelor. Prasugrel purchases started from 2010 while clopidogrel data covered the whole study period. We found incidence of SFINX class D interactions to decrease in clopidogrel users after 2009 settling down to less than ten percent in 2010-2013. Ticagrelor C class interactions were the most common; almost half of the patients had a $\mathrm{C}$ type interactive concomitant drug treatment in 2012-2013. In most of these cases, ticagrelor was not the victim drug but influenced the metabolism of simvastatin.

All the included pharmacodynamic interactions in this study were manageable by dose adjustments. In the clopidogrel group, the most common pharmacokinetic interactions were the most serious ones (Table 2). At the time of study planning, there were $25 \mathrm{D}$ level interactions listed for ticagrelor in SFINX [9] (cited online 18 June 2014). In the study data we found, however, only five drug pairs causing D class interactions with ticagrelor (Table 2).

In the present type of study, we cannot assure that the patients finally were exposed to the interactive combinations but defined the potential for such interactions as judged from purchases during ongoing OAP treatment. The interactive drugs do not usually represent certain therapeutic areas especially in case of drug pairs in pharmacokinetic interactions. Thus, it is difficult to take enormous amount detailed information into account when prescribing OAPs by a physician in everyday practice. Further, a growing number of prescribers are a factor leading to increased risk of drug-drug interactions. It is, however, very common that different physicians prescribe different drugs to one patient. Therefore, electronic tools are valuable in daily practice. Electronic prescriptions are currently in mandatory use in Finland. The prescriptions are visible nationwide for the practitioners, which will eventually help in the evaluation of polypharmacy.

In conclusion, warfarin and ibuprofen were the most commonly used concomitant medications known to cause pharmacodynamic interactions and potentially increasing the bleeding risk in OAP-treated patients. The history of major bleeding was not associated with decreased use of warfarin, NSAIDs, or SSRIs, and thus their risk of interactions with OAP after discharge. Esomeprazole and omeprazole were used in clopidogrel-treated patients potentially increasing the patients' coagulation risk despite the available alternatives for gastric protection. Interactions of OAPs with serotonergic SSRIs and tramadol, or of ticagrelor with simvastatin, did not seem to be well recognized.

Acknowledgements Open access funding provided by University of Turku (UTU) including Turku University Central Hospital.

Authors' contributions TP, HK, PH, ER, JA, and VK participated in design the study. TP and HK collected the data and conducted the analyses. TP, HK, PH, ER, JA, and VK contributed to the interpretation of the 
results. TP and VK drafted the manuscript. TP, HK, PH, ER, JA and VK accepted the final version of the manuscript.

Funding information The study was fully sponsored by AstraZeneca Nordic Baltic (study ID ME-CV-1306).

\section{Compliance with ethical standards}

This was an observational register study with no contact or intervention directed to the patients. The study was conducted by following the European Network of Centres for Pharmacoepidemiology and Pharmacovigilance (ENCePP) as well as the guidelines for good pharmacoepidemiology practice (GPP) [21, 22]. The protocol was reviewed and approved by the Ethical Review Board of Hospital District of Helsinki and Uusimaa, Finland (131/13/03/00/14), and the study was registered into the EUPAS e-register of studies (EUPAS6161). Data permits were applied from National Institute for Health and Welfare (THL/522/5.05.00/2014), Social Insurance Institution (Kela 21/522/2014), and Statistics Finland (TK-53-532-14). The identification numbers of the patients were encrypted by these authorities before data delivery to the researchers.

Conflict of interest T. Prami was, and H. Khanfir is an employee of EPID Research that is a contract research organization. EPID Research performs commissioned pharmacoepidemiological studies and thus, its employees have been and are currently working in collaboration with several pharmaceutical companies. Since January 2018, T. Prami has been working for the Finnish Medicines Agency Fimea. P. Hasvold is an employee of the sponsor, AstraZeneca Nordic Baltic. E. Reissell and J. Airaksinen declare they have no conflicts of interest. V. Kytö: payment for lectures: Bayer, Boehringer-Ingelheim. Consulting fee: AstraZeneca.

Open Access This article is distributed under the terms of the Creative Commons Attribution 4.0 International License (http:// creativecommons.org/licenses/by/4.0/), which permits unrestricted use, distribution, and reproduction in any medium, provided you give appropriate credit to the original author(s) and the source, provide a link to the Creative Commons license, and indicate if changes were made.

\section{References}

1. Ferri N, Corsini A, Bellosta S (2013) Pharmacology of the new P2Y12 receptor inhibitors: insights on pharmacokinetic and pharmacodynamic properties. Drugs 73(15):1681-1709. https://oi.org/ 10.1007/s40265-013-0126-Z

2. Kytö V, Prami T, Khanfir H, Hasvold P, Reissell E, Airaksinen J (2019) Usage of PCI and long-term cardiovascular risk in postmyocardial infarction patients: a nationwide registry cohort study from Finland. BMC Cardiovasc Disord 19(1):123. https://doi.org/ 10.1186/s12872-019-1101-8

3. Wang ZY, Chen M, Zhu LL, Yu LS, Zeng S, Xiang MX, Zhou Q (2015) Pharmacokinetic drug interactions with clopidogrel: updated review and risk management in combination therapy. Ther Clin Risk Manag 11:449-467. https://doi.org/10.2147/TCRM.S80437

4. Teng R (2015) Ticagrelor: pharmacokinetic, pharmacodynamic and pharmacogenetic profile: an update. Clin Pharmacokinet 54(11): 1125-1138. https://doi.org/10.1007/s40262-015-0290-2

5. Mackenzie IS, Coughtrie MW, MacDonald TM, Wei L (2010) Antiplatelet drug interactions. J Intern Med 268(6):516-529. https://doi.org/10.1111/j.1365-2796.2010.02299.x
6. Delavenne X, Magnin M, Basset T, Piot M, Mallouk N, Ressnikoff D, Garcin A, Laporte S, Garnier P, Mismetti P (2013) Investigation of drug-drug interactions between clopidogrel and fluoxetine. Fundam Clin Pharmacol 27(6):683-689. https://doi.org/10.1111/ fcp. 12021

7. Angiolillo DJ, Gibson CM, Cheng S, Ollier C, Nicolas O, Bergougnan L, Perrin L, LaCreta FP, Hurbin F, Dubar M (2011) Differential effects of omeprazole and pantoprazole on the pharmacodynamics and pharmacokinetics of clopidogrel in healthy subjects: randomized, placebo-controlled, crossover comparison studies. Clin Pharmacol Ther 89(1):65-74. https://doi.org/10.1038/clpt. 2010.219

8. Prami T, Khanfir H, Deleskog A, Hasvold P, Kytö V, Reissell E, Airaksinen J (2016) Clinical factors associated with initiation of and persistence with ADP receptor-inhibiting oral antiplatelet treatment after acute coronary syndrome: a nationwide cohort study from Finland. BMJ Open 6(11):e012604. https://doi.org/10.1136/ bmjopen-2016-012604

9. Böttiger Y, Laine K, Andersson ML, Korhonen T, Molin B, Ovesjo ML, Tirkkonen T, Rane A, Gustafsson LL, Eiermann B (2009) SFINX-a drug-drug interaction database designed for clinical decision support systems. Eur J Clin Pharmacol 65(6):627-633. https:// doi.org/10.1007/s00228-008-0612-5

10. Jernberg T, Hasvold P, Henriksson M, Hjelm H, Thuresson M, Janzon M (2015) Cardiovascular risk in post-myocardial infarction patients: nationwide real world data demonstrate the importance of a long-term perspective. Eur Heart J 36(19):1163-1170. https://doi. org/10.1093/eurheartj/ehu505

11. Roffi M, Patrono C, Collet JP, Mueller C, Valgimigli M, Andreotti F, Bax JJ, Borger MA, Brotons C, Chew DP, Gencer B, Hasenfuss G, Kjeldsen K, Lancellotti P, Landmesser U, Mehilli J, Mukherjee D, Storey RF, Windecker S, Group ESCSD (2016) 2015 ESC Guidelines for the management of acute coronary syndromes in patients presenting without persistent ST-segment elevation: task force for the management of acute coronary syndromes in patients presenting without persistent ST-segment elevation of the European Society of Cardiology (ESC). Eur Heart J 37(3):267-315. https:// doi.org/10.1093/eurheartj/ehv320

12. Ibanez B, James S, Agewall S, Antunes MJ, Bucciarelli-Ducci C, Bueno H, Caforio ALP, Crea F, Goudevenos JA, Halvorsen S, Hindricks G, Kastrati A, Lenzen MJ, Prescott E, Roffi M, Valgimigli M, Varenhorst C, Vranckx P, Widimsky P, Group ESCSD (2018) 2017 ESC Guidelines for the management of acute myocardial infarction in patients presenting with ST-segment elevation: the task force for the management of acute myocardial infarction in patients presenting with ST-segment elevation of the European Society of Cardiology (ESC). Eur Heart J 39(2):119177. https://doi.org/10.1093/eurheartj/ehx393

13. Schjerning Olsen AM, Gislason GH, McGettigan P, Fosbol E, Sorensen R, Hansen ML, Kober L, Torp-Pedersen C, Lamberts M (2015) Association of NSAID use with risk of bleeding and cardiovascular events in patients receiving antithrombotic therapy after myocardial infarction. JAMA 313(8):805-814. https://doi.org/10. 1001/jama.2015.0809

14. Ferreiro JL, Ueno M, Capodanno D, Desai B, Dharmashankar K, Darlington A, Charlton RK, Bass TA, Angiolillo DJ (2010) Pharmacodynamic effects of concomitant versus staggered clopidogrel and omeprazole intake: results of a prospective randomized crossover study. Circ Cardiovasc Interv 3(5):436-441. https:// doi.org/10.1161/CIRCINTERVENTIONS.110.957829

15. Moceri P, Doyen D, Cerboni P, Ferrari E (2011) Doubling the dose of clopidogrel restores the loss of antiplatelet effect induced by esomeprazole. Thromb Res 128(5):458-462. https://doi.org/10. 1016/j.thromres.2011.06.029

16. Tragni E, Casula M, Pieri V, Favato G, Marcobelli A, Trotta MG, Catapano AL (2013) Prevalence of the prescription of potentially 
interacting drugs. PLoS One 8(10):e78827. https://doi.org/10.1371/ journal.pone.0078827

17. Frelinger AL 3rd, Lee RD, Mulford DJ, Wu J, Nudurupati S, Nigam A, Brooks JK, Bhatt DL, Michelson AD (2012) A randomized, 2period, crossover design study to assess the effects of dexlansoprazole, lansoprazole, esomeprazole, and omeprazole on the steady-state pharmacokinetics and pharmacodynamics of clopidogrel in healthy volunteers. J Am Coll Cardiol 59(14): 1304-1311. https://doi.org/10.1016/j.jacc.2011.12.024

18. Farhat N, Haddad N, Crispo J, Birkett N, McNair D, Momoli F, Wen SW, Mattison DR, Krewski D (2019) Trends in concomitant clopidogrel and proton pump inhibitor treatment among ACS inpatients, 2000-2016. Eur J Clin Pharmacol 75(2):227-235. https://doi. org/10.1007/s00228-018-2564-8

19. Hosia-Randell HM, Muurinen SM, Pitkala KH (2008) Exposure to potentially inappropriate drugs and drug-drug interactions in elderly nursing home residents in Helsinki, Finland: a cross-sectional study.
Drugs Aging 25(8):683-692. https://doi.org/10.2165/00002512200825080-00005

20. Patel PA, Augoustides JG (2010) Progress in platelet medicine: focus on stent thrombosis and drug resistance. J Cardiothorac Vasc Anesth 24(4):722-727. https://doi.org/10.1053/j.jvca.2010. 04.017

21. Ispe (2008) Guidelines for good pharmacoepidemiology practices (GPP). Pharmacoepidemiol Drug Saf 17(2):200-208. https://doi. org/10.1002/pds. 1471

22. Public Policy Committee ISoP (2016) Guidelines for good pharmacoepidemiology practice (GPP). Pharmacoepidemiol Drug Saf 25(1):2-10. https://doi.org/10.1002/pds.3891

Publisher's note Springer Nature remains neutral with regard to jurisdictional claims in published maps and institutional affiliations. 